open $\bigcirc$ Access
Authors' contribution:

A) conception and design of the study

B) acquisition of data

C) analysis and interpretation of data

D) manuscript preparation

E) obtaining funding

Received: 14.02 .2020

Accepted: 01.02.2021

\section{Multilateral teaching in physical education improves resilience and self-efficacy in adolescents and could help reduce bullying behaviors}

\author{
Gianpiero Greco ${ }^{* 1 A-D}$ (D) \\ ${ }^{1}$ Department of Basic Medical Sciences, Neuroscience and Sense Organs, University of \\ Study of Bari, Italy
}

*Correspondence: Gianpiero Greco; Piazza Giulio Cesare 11, 70124 Bari, Italy; e-mail: gianpierogreco.phd@yahoo.com

\begin{abstract}
Youth with higher levels of resilience and self-efficacy are less likely to engage in aggressive behaviors or be victims of bullying. Previous anti-bullying approaches have often achieved no reduction in bullying behavior. Thus, the aim of this study was to examine the effect of 12 weeks of extracurricular multilateral teaching on the risk for students (aged 14-16 years) to be involved in bullying. Sixty male students were allocated to an experimental group $(n=30)$ that performed psychoeducational activities combined with physical exercise training and team games $\left(90 \mathrm{~min}, 2 \mathrm{~d} \cdot\right.$ week $\left.^{-1}\right)$ or a control group $(n=30)$. Before and after the intervention, we used the Child and Youth Resilience Measure (CYRM-28) to assess individual capacities and resources, relationship with primary caregiver, contextual factors, and total resilience; and the Self-Efficacy Questionnaire for Children (SEQ-C) to measure academic, social, emotional, and total self-efficacy. Four participants from the experimental group withdrew. Significant improvements of crucial relevance were found for the resilience and self-efficacy scales $(p<0.05)$ in the experimental group. We found that multilateral teaching may improve resilience and self-efficacy in adolescents and make them less likely to engage in aggressive behavior or be bullied. Multilateral teaching should be considered an effective alternative to the anti-bullying approach, highlighting the crucial role of physical education teachers in the promotion of proactive educational strategies to reduce bullying behaviors.
\end{abstract}

Key words: Special education, resilience, self-efficacy, physical exercise, victimization

\title{
Introduction
}

Bullying is a controversial issue. However, there is no standard definition of bullying (Rigby, 2008), and it is difficult to establish a definition inclusive of all bullying behaviors (Lines, 2008). Research suggests bullying can be characterized as (1) a type of aggression (Pellegrini, 2004), (2) systematic and repeated (Olweus, 1993), and (3) based upon an imbalance of power (Bouman et al., 2012). These behaviors occur both directly and indirectly and can have negative social consequences. Examples of commonplace power differences in school include being able to physically hurt others, numerical (group) superiority, being more confident or assertive than others, having greater verbal dexterity, having superior social or manipulative skills, and having greater status and corresponding capacity to impose one's will on others (Rigby, 2008). Anti-bullying strategies are the main approach for addressing bullying 
in schools (Farrington \& Ttofi, 2009) and claim substantial support to address bullying. However, anti-bullying approaches are often found to achieve no reduction of bullying behavior or actually lead to increases in this type of behavior (Moore \& Woodcock, 2017a; Rigby, 2002, 2008).

Resilience is a complex construct (Kaplan, 2006) that is defined as the attainment of positive outcomes, adaptation, or developmental milestones in the face of significant adversity, risk, or stress (Goldstein \& Brooks, 2006). Different conceptualizations describe resilience as (a) a protective process, (b) the interaction of protection and risks, and (c) a conceptual tool within predictive models (Elias, Parker, \& Rosenblatt, 2006). The operational definition of resilience varies and has included hardiness, optimism, competence, self-esteem, social-skills, achievement, and the absence of pathology in the face of adversity (Prince-Embury, 2007). The research examining the relationship between bullying and resilience is not extensive (Sapouna \& Wolke, 2013), and findings include: (a) students with a strong resilience profile were less likely to engage in aggressive behaviors or be bullied than those who reported fewer developmental strengths (Donnon, 2010); (b) bullying appeared to decrease if social skills were improved in victims, and strategies of nonchalance and emotional regulation were useful (Lisboa \& Killer, 2008); and (c) resilience to bullying was improved if the student had a peer or family member with whom to disclose their feelings (Bowes, Maughan, Caspi, Moffitt, \& Arseneault, 2010; Rivers \& Cowie, 2006).

Some authors have shown that the practice of physical activity is an excellent means for the transmission of values (Portolés \& González, 2015) and helps to promote prosocial attitudes (González et al., 2016), so it can be useful in the prevention and treatment of bullying. Young people are allowed to develop resilience and self-efficacy through participation in physical activity and sport (Bandura, 2012; Schiraldi, 2011). Furthermore, the youth particularly males - with higher social self-efficacy are somewhat more likely to resist pressure to engage in risky behaviors such as delinquent behavior and being victimized (Ludwig \& Pittman, 1999). However, it seems that the amount of physical activity carried out and the type of sport practiced can act as regulators in the victimization caused by bullying (Cascales \& Prieto, 2019). For example, moderate physical activity that is geared towards disciplines such as football or athletics implies greater victimization in all dimensions, while activity oriented towards traditional martial arts or popular games involves lower victimization rates (Macarie \& Roberts, 2010). Also, in a recent systematic review, it was mentioned that few studies relate bullying to physical activity and sport (Baena \& Bosca, 2018; Holt, 2016).

Accordingly, we may speculate that multilateral teaching in physical education, a method including psychoeducational activities combining physical exercise training and team games, may be an effective alternative approach to anti-bullying (Hartmann, 2003). Therefore, the purpose of this study was to examine the effects of 12 weeks of an extracurricular multilateral teaching program on students' risk of being involved with bullying (bully and victim) through the analysis of the resilience and self-efficacy variables. It was hypothesized that multilateral teaching would improve the resilience processes and perceived self-efficacy.

\section{Methods}

\section{Study design}

The study was a 12-week high-school-based intervention that was evaluated using a randomized controlled study. Data were collected and recorded at baseline (pre-test) and after 12 weeks (post-test). After pre-test and randomization, the experimental group participated in a multilateral teaching program. The control group participated in the same program after the post-intervention assessment. The design was facilitated through the use of standardized tests, which increase the validity and reliability of data as such instruments have been developed and normalized using larger samples and have been piloted to ensure test items measure the intended data (Cohen \& Swerdlik, 2005).

\section{Participants}

Sixty male adolescents (mean age, $14.59 \pm 0.71$; range 14-16 years) from two local high schools were recruited to participate in the study. The socioeconomic status of all participants was reported as middle class. Power calculations were conducted to determine the sample size required to detect changes in the dependent measures resulting from multilateral teaching. An a priori power analysis (Faul, Erdfelder, Lang, \& Buchner, 2007) with an assumed type I error of 0.05 and a type II error rate of 0.10 (90\% statistical power) was calculated and revealed that 46 participants in total would be sufficient to observe medium "Time x Group" interaction effects. The following inclusion criteria were applied: a) male gender, b) aged 14 to 16 years old, and c) not involved in regular exercise during the 
last two years. Participants were excluded if they had a chronic pediatric disease or an orthopedic condition that would limit their ability to perform the exercise. All participants and their parents received a complete explanation in advance about the purpose of the experiment, and the parents provided written consent to the study. The study was conducted in accordance with the Declaration of Helsinki, and the protocol was approved by the local Ethics Committee. The study was conducted from April to June 2019.

\section{Procedures}

The recruitment occurred from schools in close proximity to the workplace of one of the researchers. The school staff distributed information and consent forms to all students to be recruited and their parents. Participants were verbally reminded that participation was voluntary, that they could discontinue the survey at any point, and that their responses were confidential and anonymous. Participants were instructed regarding (a) not writing their names on the survey, (b) how to respond to rating scales, and (c) how to correct responses. Participants were not given the definitions of bullying, resilience, or self-efficacy in order to avoid bias in their responses. Surveys were then provided to the participants.

Randomization into experimental $(\mathrm{n}=30$; age $14.54 \pm 0.71$ years $)$ and wait-list control groups $(\mathrm{n}=30$; age $14.63 \pm 0.72$ years) occurred after pre-intervention assessments. Participants were pair-matched based on age, and the randomization was carried out by Research Randomizer, a program published on a publicly accessible official website (www.randomizer.org). The researchers were blinded to this randomization of experimental and control group allocations. Fifty-six participants completed the post-intervention assessment, and four participants from the experimental group did not complete the study for unknown reasons.

\section{Measures}

To evaluate the effects of the multilateral teaching program, two standardized psychometric instruments were used: the Child and Youth Resilience Measure (CYRM-28) (Liebenberg, Ungar, \& Van de Vijver, 2012; Ungar \& Liebenberg, 2011) and the Self-Efficacy Questionnaire for Children (SEQ-C) (Muris, 2001; Suldo \& Shaffer, 2007).

The CYRM-28 is a 28-item instrument that measures various aspects of the resilience of children and adolescents. The scale provides a total resilience scale $(\alpha=0.86)$ and three subscales including an individual capacities and resources scale $(\alpha=0.84)$, relationship with primary caregiver scale $(\alpha=0.84)$, and contextual factors scale $(\alpha=0.83$ ). Items are scored on a 5-point Likert scale with $0=$ not at all, $1=$ a little, $2=$ somewhat, $3=$ quite a bit, and $4=$ a lot. The CYRM-28 is designed as a screening tool to explore the resources (individual, relational, and contextual) available to bolster resilience competence in the face of adversity. Individual resources are individual personal skills (e.g., "I am aware of my own strengths."), individual peer support (e.g., "I feel supported by my friends."), and individual social skills (e.g., "I know where to go in my community to get help."). Relational resources are physical caregiving (e.g., "My caregiver[s] watch me closely.") and psychological caregiving (e.g., "I talk to my caregiver[s] about how I feel."). Contextual resources are spiritual (e.g." "Spiritual beliefs are a source of strength for me."), educational (e.g., "Getting an education is important to me."), and cultural (e.g., "I am proud of my ethnic background."). Higher scores indicate a greater presence of resilience processes.

The SEQ-C is a 24-item instrument that measures various aspects of the self-efficacy of children and adolescents. The scale provides a total self-efficacy scale and three subscales: (1) academic self-efficacy (eight items), which is concerned with the perceived capability to manage one's academic affairs (e.g., "How well can you study when there are other interesting things to do?"); (2) social self-efficacy (eight items), which has to do with the perceived capability to deal with other people in an effective way (e.g., "How well can you become friends with other children?"); and (3) emotional self-efficacy (eight items), which pertains to the perceived capability of coping with negative emotions (e.g., "How well can you control your feelings?"). The SEQ-C scales have good cross-cultural validity (Minter \& Pritzker, 2017) and show a reliable to highly reliable internal consistency $(\alpha=0.78-0.85)$. Items are scored on a 5-point Likert scale with $0=$ not at all, $1=$ a little, $2=$ somewhat, $3=$ quite a bit, and $4=$ very well. A total self-efficacy score can be computed by summing all items. A high score in this questionnaire shows high self-efficacy in the specific function in question.

\section{Multilateral teaching program}

The program was performed on-site at participating schools. Participants participated in a multilateral teaching program for about 90 minutes, two extracurricular sessions per week, for a total of 24 training sessions. Each session was supervised by the primary investigator and conducted by two graduates in sport sciences and sports 
coaching specialists. Also, the mode, frequency, intensity, duration, and progression were recorded in an individual exercise log to ensure adequate training. Each training session started with a few minutes of psychoeducational activities that were also covered during the session; subsequently, a brief dynamic warm-up program, mainly consisting of calisthenics-type exercises, was performed; finally, a cool-down program, consisting of static stretching exercises, completed the session. The conditioning phase of the multilateral teaching program included cardiovascular endurance, resistance training, flexibility, and team-building activities. Flexibility was trained using both dynamic and static stretches during the warm-up or cool-down phase of each training session. During the first four weeks, the training primarily consisted of preconditioning. From the fifth week onwards, we gradually increased the intensity and volume of the training. For effective training, the principles of overload and specificity were addressed (Haff \& Triplett, 2016). The contents of the multilateral teaching program are shown in Table 1.

Table 1. Sample multilateral teaching extracurricular session by the experimental group

\begin{tabular}{|c|c|c|c|c|c|}
\hline $\begin{array}{c}\text { Psychoeducational } \\
\text { activities }\end{array}$ & Warm-up & $\begin{array}{c}\text { Cardiovascular } \\
\text { endurance }\end{array}$ & $\begin{array}{l}\text { Resistance } \\
\text { training }\end{array}$ & Team building & Cool-down \\
\hline $\begin{array}{l}\text { Topics included: } \\
\text { Respect, goal- } \\
\text { setting, self-concept } \\
\text { and self-esteem, } \\
\text { courage, resilience, } \\
\text { bullying and peer } \\
\text { pressure, self-care } \\
\text { and caring for } \\
\text { others, values, and } \\
\text { optimism and hope. }\end{array}$ & $\begin{array}{l}\text { Arm swings } \\
\text { Trunk twisting } \\
\text { High marching } \\
\text { Stride jumping } \\
\text { High knees } \\
\text { Side bending } \\
\text { Side stretching } \\
\text { Skipping leg } \\
\text { swings } \\
\text { Backwards } \\
\text { sprinting } \\
\text { Lateral shuffles }\end{array}$ & $\begin{array}{c}\text { Running } \\
\text { Walking } \\
\text { Circuits } \\
\text { Sprint intervals } \\
\text { Agility (i.e., the } \\
\text { ladder exercise) }\end{array}$ & $\begin{array}{l}\text { Jump squats } \\
\text { Lunges } \\
\text { Push-ups } \\
\text { Pull-ups } \\
\text { Curl-ups } \\
\text { Half squats } \\
\text { Long jumps } \\
\text { Planks } \\
\text { Medicine ball } \\
\text { tosses }\end{array}$ & $\begin{array}{c}\text { Volleyball } \\
\text { Basketball } \\
\text { Handball } \\
\text { Soccer } \\
\text { Modified forms of } \\
\text { the previous team } \\
\text { games }\end{array}$ & $\begin{array}{c}\text { Static stretching: } \\
\text { Achilles tendon/calf } \\
\text { stretches } \\
\text { Skier's stretches } \\
\text { Quadriceps stretches } \\
\text { Hurdler's stretches } \\
\text { Straddle stretches } \\
\text { Groin stretches } \\
\text { Back stretches } \\
\text { Archers }\end{array}$ \\
\hline $\begin{array}{l}\text { Guidelines } \\
\text { Duration: } 5 \text { minutes. } \\
\text { Topics specifically } \\
\text { covered during } \\
\text { team-building } \\
\text { activities }\end{array}$ & $\begin{array}{l}\text { Guidelines } \\
\text { Duration: } \\
10 \text { minutes. } \\
\text { Perform each } \\
\text { exercise for } 60 \\
\text { sec, } 1 \text { set }\end{array}$ & $\begin{array}{l}\text { Guidelines } \\
\text { Duration: } \\
\text { gradually from } 20 \\
\text { to } 30 \text { minutes. } \\
\text { Intensity: } 60 \text { to } \\
\text { 90\% HRmax } \\
(220 \text {-age). } \\
\text { Used HR rate } \\
\text { monitor (Polar@) } \\
\text { to ensure proper, } \\
\text { effective, and } \\
\text { safe training. } \\
\text { Progression: } \\
\text { increase duration } \\
\text { before intensity }\end{array}$ & $\begin{array}{l}\text { Guidelines } \\
\text { Duration: } \\
\text { 10-20 minutes. } \\
\text { 1-2 sets of } 8-15 \\
\text { repetitions with } \\
45 \text { sec of slow } \\
\text { walking between } \\
\text { each exercise }\end{array}$ & $\begin{array}{c}\text { Guidelines } \\
\text { Duration: about } \\
20 \text { minutes. } \\
\text { Performed at } \\
\text { the end of the } \\
\text { conditioning, } \\
\text { before the cool- } \\
\text { down. } \\
\text { Characterized by } \\
\text { a predominantly } \\
\text { playful approach } \\
\text { to encourage } \\
\text { enthusiasm, } \\
\text { socialization, and } \\
\text { participation }\end{array}$ & $\begin{array}{c}\text { Guidelines } \\
\text { Total duration: } \\
10 \text { minutes. } \\
\text { Overload: stretch } \\
\text { beyond resting length } \\
\text { but not beyond pain- } \\
\text { free ROM. } \\
\text { Duration: } \\
\text { 10-30 sec/stretch. } \\
\text { Repetitions: } 2-4, \\
\text { accumulate } 60 \text { sec } \\
\text { per exercise. } \\
\text { Progression: } \\
\text { gradual increase in } \\
\text { stretch duration or } \\
\text { repetitions }\end{array}$ \\
\hline
\end{tabular}

\section{Statistical analyses}

Statistical analyses were carried out using SAS JMP ${ }^{\circledR}$ Statistics (Version $<14.3>$, SAS Institute Inc., Cary, NC, USA, 2018). Data were presented as group mean values and standard deviations and checked for assumptions of normality that were confirmed with visual observation of univariate histograms, Q-Q plots, and skewness and kurtosis values. A multivariate analysis of variance (MANOVA) was conducted to detect group differences at baseline. A two-way ANOVA (group [experimental/control] $\times$ time [pre/post-intervention]) with repeated measures on the time dimension was conducted to examine the effect of multilateral teaching on all examined variables. When "Group x Time" interactions reached the level of significance, group-specific post hoc tests (i.e., paired t-tests) were conducted to identify the significant comparisons. 
Partial eta squared $\left(\eta_{p}^{2}\right)$ was used to estimate the magnitude of the difference within each group and was interpreted using the following criteria: small $\left(\eta_{p}^{2}<0.06\right)$, medium $\left(0.06 \leq \eta_{p}^{2}<0.14\right)$, large $\left(\eta_{p}^{2} \geq 0.14\right)$. Effect sizes for the pairwise comparisons were determined by Cohen's $d$ and interpreted as small $(0.20 \leq d<0.50)$, moderate $(0.50 \leq d<0.79)$, and large $(d \geq 0.80)$ (Cohen, 1992). The standardized Cronbach's alpha coefficient (Cohen, Manion, \& Morrison, 2011) was used as a measure of the reliability of the psychological tests (reliable: $0.70 \leq \alpha<0.80$; highly reliable: $0.80 \leq \alpha \leq 0.90)$. Statistical significance was set at $p<0.05$.

\section{Results}

Four participants from the experimental group withdrew, and thus fifty-six students completed the study. No injuries or other health problems were noted in the participants over the 12 weeks. All the participants of the experimental group showed satisfaction and reported a desire to continue practicing physical activity afterwards. The groups did not differ significantly at baseline in all the dependent variables $(p=0.926)$. Table 2 shows the group changes in total resilience and self-efficacy and related subscales after 12 weeks.

Table 2. Changes in resilience and self-efficacy scales after 12-week multilateral teaching

\begin{tabular}{lcccccc}
\hline & \multicolumn{2}{c}{ Experimental group $(\mathrm{n}=26)$} & \multicolumn{3}{c}{ Control group $(\mathrm{n}=30)$} \\
\hline & Baseline & Post-test & $\Delta$ & Baseline & Post-test & $\Delta$ \\
\hline CYRM-28 Resilience scales & & & & & & \\
\hline Individual capacities and resources & $2.92(0.52)$ & $3.07(0.52) \dagger^{*}$ & $0.14(0.15)$ & $3.11(0.70)$ & $3.12(0.65)$ & $0.01(0.24)$ \\
Relationship with primary caregiver & $3.06(0.65)$ & $3.18(0.59) \dagger^{*}$ & $0.13(0.20)$ & $3.01(0.66)$ & $2.95(0.63)$ & $-0.06(0.18)$ \\
Contextual factors & $2.55(0.67)$ & $2.72(0.64) \dagger^{*}$ & $0.17(0.23)$ & $2.53(0.84)$ & $2.42(0.66)$ & $-0.10(0.38)$ \\
Total resilience & $2.84(0.39)$ & $2.99(0.37) \dagger^{*}$ & $0.15(0.12)$ & $2.88(0.48)$ & $2.83(0.40)$ & $-0.05(0.16)$ \\
\hline SEQ-C Self-efficacy scales & & & & & & \\
\hline Academic self-efficacy & $2.58(0.70)$ & $2.88(0.59) \dagger^{*}$ & $0.31(0.74)$ & $2.70(0.65)$ & $2.67(0.61)$ & $-0.03(0.18)$ \\
Social self-efficacy & $2.58(0.64)$ & $2.69(0.55) \dagger^{*}$ & $0.12(0.33)$ & $2.63(0.61)$ & $2.60(0.62)$ & $-0.03(0.18)$ \\
Emotional self-efficacy & $2.46(0.51)$ & $2.73(0.45) \dagger^{*}$ & $0.27(0.45)$ & $2.53(0.57)$ & $2.47(0.57)$ & $-0.07(0.25)$ \\
Total self-efficacy & $2.54(0.33)$ & $2.77(0.26) \dagger^{*}$ & $0.23(0.28)$ & $2.62(0.27)$ & $2.58(0.29) *$ & $-0.04(0.12)$ \\
\hline
\end{tabular}

Note: values are presented as mean $( \pm \mathrm{SD}) ; \Delta$ : pre - to post-training changes; $\uparrow$ Significant "Group $\mathrm{x}$ Time" interaction: significant effect of the intervention $(p<0.05)$. *Significantly different from pre-test $(p<0.05)$.

\section{Resilience}

Individual capacities and resources: A significant "Time $\mathrm{x}$ Group" interaction $\left(\mathrm{F}_{1.54}=6.09, p=0.017, \eta_{p}^{2}=0.10\right)$ and main effect of "Time" $\left(\mathrm{F}_{1.54}=7.21, p=0.001, \eta_{p}^{2}=0.12\right)$ were found, but no significant main effects of "Group" were detected.

Relationship with primary caregiver: Statistical analysis revealed only a significant "Time x Group" interaction $\left(\mathrm{F}_{1.54}=14.15, p<0.001, \eta_{p}^{2}=0.21\right)$, whereas no significant main effects of "Time" or "Group" were detected.

Contextual factors: A significant "Time x Group" interaction $\left(\mathrm{F}_{1.54}=10.25, p=0.002, \eta_{p}^{2}=0.16\right)$ was found, but significant main effects of "Time" or "Group" were not.

Total resilience: A significant "Time x Group" interaction $\left(\mathrm{F}_{1.54}=27.36, p<0.001, \eta_{p}^{2}=0.34\right)$ and main effect of "Time" $\left(\mathrm{F}_{1.54}=5.97, p=0.018, \eta_{p}^{2}=0.10\right)$ were found, but no significant main effects of "Group" were detected.

The post hoc analyses revealed a significant increase in scores from pre - to post-test for the experimental group in individual capacities and resources $(p<0.001, d=0.99)$, relationship with primary caregiver $(p=0.002$, $d=0.61)$, contextual factors $(p=0.001, d=0.73)$, and total resilience $(p<0.001, d=1.27)$.

\section{Self-efficacy}

Academic self-efficacy: A significant "Time x Group" interaction $\left(\mathrm{F}_{1.54}=6.03, p=0.017, \eta_{p}^{2}=0.10\right)$ was found, but no significant main effects of "Time" or "Group" were detected. 
Social self-efficacy: A significant "Time x Group" interaction $\left(\mathrm{F}_{1.54}=4.59, p=0.037, \eta_{p}^{2}=0.08\right)$ was found, but significant main effects of "Time" or "Group" were not.

Emotional self-efficacy: Statistical analysis revealed a significant "Time x Group" interaction $\left(\mathrm{F}_{1.54}=12.15\right.$, $\left.p=0.001, \eta_{p}^{2}=0.18\right)$ and significant main effect of "Time" $\left(\mathrm{F}_{1.54}=4.42, p=0.040, \eta_{p}^{2}=0.08\right)$, whereas no significant main effect of "Group" was detected.

Total self-efficacy: A significant "Time $\mathrm{x}$ Group" interaction $\left(\mathrm{F}_{1.54}=24.41, p<0.001, \eta_{p}^{2}=0.31\right)$ and significant main effect of "Time" $\left(\mathrm{F}_{1.54}=11.19, p=0.001, \eta_{p}^{2}=0.17\right)$ were found. No significant main effect of "Group" was detected.

The post hoc analyses revealed significant improvements from pre - to post-test for the experimental group in academic self-efficacy ( $p=0.043, d=0.41)$, social self-efficacy $(p=0.041, d=0.34)$, emotional self-efficacy $(p=0.006, \mathrm{~d}=0.60)$, and total self-efficacy $(p<0.001, d=0.82)$. Also, the control group showed worsening in total self-efficacy $(p=0.043, d=0.35)$ after 12 weeks.

\section{Discussion}

The purpose of this study was to examine the effects of a 12-week extracurricular multilateral physical education program on male students' risk of being involved in bullying (bully and victim) through analysis of the variables of resilience and self-efficacy. The results provided valid and reliable evidence that psychoeducational activities combined with physical exercise training and team games could be an effective alternative method for improving well-being, including resilience and self-efficacy (Hartmann, 2003). In addition, interventions using this approach should promote an individual's ability to cope with the effects of bullying. Significant improvements were found in the experimental group for levels of overall resilience and resilience sub-factors, as well as for total self-efficacy and self-efficacy subscales. Therefore, our hypothesis has been confirmed and the results agree with previous studies showing the effectiveness of a multilateral teaching program in promoting prosocial attitudes (González et al., 2016) and the transmission of values (Portolés \& González, 2015), as well as the development of resilience and self -efficacy (Bandura, 2012; Schiraldi, 2011) in young people. Furthermore, the non-competitive nature of multilateral teaching could involve lower victimization rates caused by bullying (Cascales \& Prieto, 2019; Macarie \& Roberts, 2010), and higher social self-efficacy could allow resistance to pressure to engage in risky behaviors (Ludwig \& Pittman, 1999).

For the experimental group, positive changes in resilience showed a moderate to large effect size for all subscales and total resilience. This is an important achievement because students who report higher levels of resilience may be less likely to engage in aggressive behavior or be bullied (Donnon, 2010; Lisboa \& Killer, 2008; Rigby, 2008). Significantly improved relationships with primary caregivers have been particularly important as family factors, including warm relationships and positive home environments, are associated with increased resilience to bullying (Bowes et al., 2010). It has been shown that resilience to bullying behaviors is improved when people can reveal their experiences to a family member (Rivers \& Cowie, 2006). Furthermore, significant improvements in available individual, relational, and contextual resources support resilience competence in the face of adversity (Fischetti, Cataldi, Di Terlizzi, \& Greco, 2019; Goldstein \& Brooks, 2006; Kaplan, 2006; Naglieri \& LeBuffe, 2006; Prince-Embury, 2007) and, thus, bullying (Bowes et al., 2010; Donnon, 2010; Greco, Cataldi, \& Fischetti, 2019b; Lisboa \& Killer, 2008; Rivers \& Cowie, 2006; Sapouna \& Wolke, 2013).

Our study showed increases with a large effect size for total self-efficacy and with a small to moderate effect for the subscales. However, the control group exhibited decreases for total self-efficacy with a small effect size, and this suggests that intervention had a greater effect on self-efficacy outcomes (Bandura, 2012). Since the victims of bullying report lower self-efficacy than non-victims (Moore \& Woodcock, 2017b), the result that total self-efficacy improved for the experimental group and decreased for the control group suggests that the intervention could improve participants' abilities to cope with bullying (Ludwig \& Pittman, 1999). Also, externalizing and antisocial behaviors among youth are of pressing concern and are considered a major public health problem (Krug, Mercy, Dahlberg, \& Zwi, 2002). Multilateral teaching could be an effective alternative intervention for the treatment of externalizing behaviors. Our results agree with studies that have suggested motor and sport activities reduce externalizing behaviors (Zhou et al., 2007) and improve psychological (Fischetti, Latino, Cataldi, \& Greco, 2019) and physical fitness (Fischetti \& Greco, 2017; Greco, Cataldi, \& Fischetti, 2019a), cognitive functions, and, specifically, executive functions in youth (Diamond \& Lee, 2011). 
Some limitations may limit the results of the current study. Given that the study only examined male participants from two high schools, the findings should be interpreted cautiously, as they may be the result of a localized effect. Also, as noted in the literature review, both bullying and resilience are complex constructs and lack an agreed academic definition. This presents questions in terms of whether the definitions used in the current study adequately operationalize the constructs. Future research should expand the definition of resilience and bullying. Finally, psychoeducational activities may have had a confounding effect on combined physical exercise training. However, psychoeducational activity is naturally carried out by an experienced coach during physical and sports education sessions, so we can consider this limit irrelevant.

This study has some important strengths, i.e., it proposes an alternative approach to educational policy and suggests that instead of focusing resources towards eliminating bullying behaviors, the policy should focus on promoting mental health through the development of well-being. Furthermore, the results obtained are of crucial relevance (i.e., moderate to large effect size) and reinforce those previously found in a few studies that relate bullying to physical activity and sport (Baena \& Bosca, 2018; Holt, 2016). Future research should examine the multilateral teaching program's effects on different population samples and consider students with certain vulnerabilities (e.g., deficient gross motor skills), as doing so could help diminish bullying (Bejerot, Plenty, Humble, \& Humble, 2013; Healy, 2014).

In conclusion, the findings suggest that a multilateral teaching program based on psychoeducational activities combined with physical exercise training and team games may improve resilience and self-efficacy in male adolescents and make them less likely to engage in aggressive behavior or be bullied. Evidence supports the assertion that anti-bullying policies are inconsistent; therefore, multilateral teaching in physical education should be considered an alternative practice for improving individuals' ability to cope with the effects of bullying and an effective alternative to the failing anti-bullying approach used by institutions. Consequently, we must highlight the fact that the role of physical education teachers is noteworthy in the promotion of proactive educational strategies to reduce bullying behaviors. During training sessions and competitions, they can introduce conflict resolution and reduce the focus on competitiveness (Hand, 2016; López-Castedo, Álvarez, Domínguez, \& Álvarez, 2018).

\section{Ethics approval and informed consent}

All procedures performed in studies involving human participants were in accordance with the ethical standards of the University Institutional Review Board and with the 1964 Helsinki declaration and its later amendments or comparable ethical standards.

\section{Competing interests}

The author declared no potential conflicts of interest with respect to the research, authorship, and/or publication of this article.

\section{Funding}

No sources of funding were used to assist in the preparation of this manuscript.

\section{References}

Baena, A. C. M., \& Boscá, J. F. (2018). Acoso escolar y Educación Física: una revisión sistemática [Bullying in schools and Physical Education: A systematic review]. Retos: nuevas tendencias en educación fisica, deporte y recreación, 34, 412-419.

Bandura, A. (2012). On the functional properties of perceived self-efficacy revisited. Journal of Management, 38, 9-44.

Bejerot, S., Plenty, S., Humble, A., \& Humble, M. B. (2013). Poor motor skills: a risk marker for bully victimization. Aggressive Behaviour 39(6), 453-461. https://doi.org/10.1002/ab.21489

Bouman, T., van der Meulen, M., Goossens, F., Olthaf, T., Vermande, M., \& Aleva, E. (2012). Peer and self-reports of victimization and bullying: Their differential association with internalizing problems and social adjustment. Journal of School Psychology, 50(6), 759-774.

Bowes, L., Maughan, B., Caspi, A., Moffitt, T., \& Arseneault, L. (2010). Families promote emotional and behavioral resilience to bullying: Evidence of an environmental effect. Journal of Child Psychology and Psychiatry, 51(7), 809-814. 
Cascales, J.Á.M., \& Prieto, M.J.R. (2019). Incidencia de la práctica de actividad física y deportiva como reguladora de la violencia escolar [Incidence of the practice of physical and sports activity as a regulator of school violence]. Retos: nuevas tendencias en educación física, deporte y recreación, (35), 54-60.

Cohen, J. (1992). A Power Primer. Psychological Bulletin, 112(1), 155-159.

Cohen, L., Manion, L., \& Morrison, K. (2011). Research Methods in Education (7 ${ }^{\text {th }}$ ed.) (pp. 639-640). Oxford, UK: Routledge.

Cohen, R., \& Swerdlik, M. (2005). Psychological testing and assessment. Boston: McGraw Hill.

Diamond, A., \& Lee, K. (2011). Interventions shown to aid executive function development in children 4 to 12 years old. Science, 333, 959-964. http://dx.doi.org/10.1126/science.1204529.

Donnon, T. (2010). Understanding how resiliency development influences adolescent bullying and victimization. Canadian Journal of School Psychology, 25(1), 101-113.

Elias, M., Parker, S., \& Rosenblatt, J. (2006). Building educational opportunity. In S. Goldstein \& R. Brooks (Eds.), Handbook of resilience in children (pp. 315-336). New York: Springer.

Farrington, P., \& Ttofi, M. (2009). School-based programs to reduce bullying and victimization. Campbell Systematic Review, Oslo: Campbell Collaboration.

Faul, F., Erdfelder, E., Lang, A. G., \& Buchner, A. (2007). G* Power 3: A flexible statistical power analysis program for the social, behavioral, and biomedical sciences. Behavior research methods, 39(2), 175-191.

Fischetti, F., Cataldi, S., Di Terlizzi, P. G., \& Greco, G. (2019). Multilateral methodology in physical education improves coping skills, resilience and physical fitness in drug addicts. Journal of Human Sport and Exercise. https://doi. org $/ 10.14198 /$ jhse. 2020.152 .11

Fischetti, F., \& Greco, G. (2017). Multilateral methods in Physical Education improve physical capacity and motor skills performance of the youth. Journal of Physical Education and Sport, 17(Suppl 4), 2161-2168. https://doi.org/10.7752/ jpes.2017.s4223

Fischetti, F., Latino, F., Cataldi, S., \& Greco, G. (2019). Gender Differences in Body Image Dissatisfaction: The Role of Physical Education and Sport. Journal of Human Sport ond Exercise. https//doi.org/10.14198/jhse.2020.152.01

Goldstein, S., \& Brooks, R. (2006). Why study resilience? In S. Goldstein \& R. Brooks (Eds.), Handbook of resilience in children (pp. 3-16). New York: Springer.

González, J. I. Á., Ortega, F. Z., Garófano, V. V., Martínez, A. M., Sánchez, S. G., \& Díaz, M. E. (2016). Actividad física de adolescentes: implicación de sustancias nocivas, modalidad practicada y familia [Physical activity of adolescents: involvement of harmful substances, practiced modality and family]. 13Psicologia Escolar e Educacional, SP. Volume 20, Número 1, Janeiro/Abril de 2016: 13-22. http://dx.doi.org/10.1590/2175-3539/2015/0201908

Greco, G., Cataldi, S., \& Fischetti, F. (2019a). Effectiveness of a Short After-School Intervention on Physical Fitness in School-Aged Children. Ricerche di Pedagogia e Didattica. Journal of Theories and Research in Education, 14(1), 143-164. doi: 10.6092/issn.1970-2221/9217

Greco, G., Cataldi, S., \& Fischetti, F. (2019b). Karate as anti-bullying strategy by improvement resilience and self-efficacy in school-age youth. Journal of Physical Education and Sport, 19(Suppl 5), 1863-1870. https//doi.org/10.7752/ jpes.2019.s5276

Haff, G. G., \& Triplett, N. T. (Eds.). (2016). Essentials of strength training and conditioning 4th edition. Champaign, IL: Human kinetics.

Hand, K. E. (2016). Creating a Bully-free Environment in Physical Education. Journal of Physical Education, Recreation \& Dance, 87(7), 55-57.

Hartmann, D. (2003). Theorizing sport as social intervention: A view from the grassroots. Quest, 55, 118-140.

Healy, S. (2014). Preventing bullying in inclusive physical education practical strategies for teachers. Palestra $28,42-$ 46.

Holt, N. L. (Ed.). (2016). Positive youth development through sport. New York, NY: Routledge.

Kaplan, H. (2006). Understanding the concept of resilience. In S. Goldstein \& R. Brooks (Eds.), Handbook of resilience in children (pp. 39-48). New York: Springer.

Krug, E.G., Mercy, J.A., Dahlberg, L.L., \& Zwi, A.B. (2002). World report on violence and health. Lancet, 360(9339), 1083-88. http://dx.doi.org/10.1016/S0140-6736(02)11133-0

Liebenberg, L., Ungar, M., \& Van de Vijver, F. (2012). Validation of the child and youth resilience measure-28 (CYRM28) among Canadian youth. Research on Social Work Practice, 22(2), 219-226.

Lines, D. (2008). The bullies: Understanding bullies and bullying. London: Jessica Kingsley.

Lisboa, C., \& Killer, S. (2008). Coping with peer bullying and resilience promotion: Data from Brazilian at-risk children. International Journal of Psychology, 43, 711. 
López-Castedo, A., Álvarez, D., Domínguez, J., \& Álvarez, E. (2018). Expressions of school violence in adolescence. Psicothema, 30(4), 395-400.

Ludwig, K. B., \& Pittman, J. F. (1999). Adolescent prosocial values and self-efficacy in relation to delinquency, risky sexual behavior, and drug use. Youth \& Society, 30(4), 461-482.

Macarie, I., \& Roberts, R. (2010). Martial arts and mental health. Contemporary Psychotherapy, 2, 1-4.

Minter, A., \& Pritzker, S. (2017). Measuring adolescent social and academic self-efficacy: cross-ethnic validity of the SEQ-C. Research on Social Work Practice, 27(7), 818-826.

Moore, B., \& Woodcock, S. (2017a). Resilience to bullying: Towards an alternative to the anti-bullying approach. Educational Psychology in Practice, 33(1), 65-80.

Moore, B., \& Woodcock, S. (2017b). Resilience, bullying, and mental health: Factors associated with improved outcomes. Psychology in the Schools, 54(7), 689-702.

Muris, P. (2001). A brief questionnaire for measuring self-efficacy in youths. Journal of Psychopathology and behavioral Assessment, 23(3), 145-149.

Naglieri, J., \& LeBuffe, P. (2006). Measuring resilience in children. In S. Goldstein \& R. Brooks (Eds.), Handbook of resilience in children (pp. 107-123). New York: Springer.

Olweus, D. (1993). Bullying at school. Oxford: Blackwell.

Pellegrini, A. (2004). Bullying during the middle school years. In C. Saunders \& G. Pyne (Eds.), Bullying: Implications for the classroom (pp. 177-202). New York: Elsevier Academic Press.

Portolés, A., \& González, J. (2015). Rendimiento académico y correspondencias con indicadores de salud física y psicológica [Academic performance and correspondence with indicators of physical and psychological health]. Sportis, 1, 164-181. doi: 10.17979/sportis.2015.1.2.1409

Prince-Embury, S. (2007). Resilience scales for children and adolescents: A profile of personal strengths. Minneapolis: Pearson.

Rigby, K. (2002). A meta-evaluation of methods and approaches to reducing bullying in pre-schools and early primary school in Australia. Canberra: Commonwealth Attorney-General's Department.

Rigby, K. (2008). Children and bullying: How parents and educators can reduce bullying at schools. Carlton, Victoria: Blackwell.

Rivers, I., \& Cowie, H. (2006). Bullying and homophobia in UK schools: A perspective on factors affecting resilience and recovery. Journal of Gay \& Lesbian Issues in Education, 3(4), 11-43.

Sapouna, M., \& Wolke, D. (2013). Resilience to bullying victimization: The role of individual, family and peer characteristics. Child Abuse and Neglect, 37(11), 997-1006.

Schiraldi, G.R. (2011). The Complete Guide to Resilience. Ashburn, VA: Resilience Training International.

Suldo, S. M., \& Shaffer, E. J. (2007). Evaluation of the self-efficacy questionnaire for children in two samples of American adolescents. Journal of Psychoeducational Assessment, 25(4), 341-355.

Ungar, M., \& Liebenberg, L. (2011). Assessing resilience across cultures using mixed methods: Construction of the child and youth resilience measure. Journal of Mixed Methods Research, 5(2), 126-149.

Zhou, Q., Hofer, C., Eisenberg, N., Reiser, M., Spinrad, T. L., \& Fabes, R. A. (2007). The developmental trajectories of attention focusing, attentional and behavioral persistence, and externalizing problems during school-age years. Developmental Psychology, 43, 369-385. http://dx.doi.org/10.1037/0012-1649.43.2.369.

This is Open Access article distributed under the terms of CC-BY-NC-ND 4.0 International License. 